\title{
Recruitment into psychiatry ${ }^{\dagger}$
}

\author{
David Storer
}

This month's Bulletin contains three articles covering various aspects of recruitment to the psychiatric specialities.

The paper by Pidd (1999, this issue) covers the unexciting, but essential, topic of how we count and record the medical staff we already have in psychiatry. That by Cottrell (1999, this issue) deals with the vital matter of how we interest medical undergraduates in our subject so that they are encouraged to go on to join us in our speciality and that by Davies \& Schlich (1999, this issue) looks at the widely held belief that general psychiatry is becoming an increasingly unpopular speciality.

We now know that the argument for the need for 1000 extra medical school places per year has been successful and that there are to be new undergraduate schools at Keele. Warwick and Durham. This is good news, as ultimately we will only fill our postgraduate training posts by increasing the field from which we recruit. However, psychiatry is not the only speciality needing to expand and much of the output of the new schools will be encouraged to go into general practice. Cottrell's paper explains how psychiatry is well placed to increase the proportion of medical graduates entering our speciality.

However, such new recruits do need to like what they see once they enter the speciality. Davies \& Schlich produce some evidence to confirm the impression most of us gain from at least a substantial minority of trainees that, as far as general psychiatry is concerned, they are not attracted by the quality of life enjoyed by the consultants with whom they work. I have argued previously (Storer, 1997) that we need to be more pro-active in improving the lot of the consultant.

In order to make our case more effectively we need hard data. The College census has, over the years, gradually improved the quality of our data collection and has been of great benefit in strengthening our representatives' hands in the annual medical workforce negotiations with the Department of Health. However, its limitations and dated methodology, have become increasingly obvious and Pidd explains how we are planning to improve our data collection in the College. The eventual aim is to have an ongoing system so that we can see the situation at any one time rather than rely on a labour intensive annual exercise which is, of necessity, out of date as soon as it published.

\section{References}

COTTREL, D. (1999) Recruitment, undergraduate education and the possible impact of tomorrow's doctors. Psychiatric Bulletin, 23, 582-584.

DAviES, M. \& SCHLCH, T. (1999) A survey of factors determining whether senior and specialist registrars choose or reject a career in general adult psychiatry. Psychiatric Bulletin, 23, 607-609.

PIDD, S. (1999) The College census. Psychiatric Bulletin, 23. 585-586.

STORER, D. (1997) Things have to get better. Psychiatric Bulletin. 21, 737-738.

David Storer, Consultant Liaison Psychiatrist, Leeds General Infirmary, Great George Street, Leeds LS1 3EX

'See pages 582-586 and 607-609, this issue. 